\title{
WE "MEME" BUSINESS: EXPLORING MALAYSIAN YOUTHS' INTERPRETATION OF INTERNET MEMES IN SOCIAL MEDIA MARKETING
}

\author{
Kee-Man Chuah* \\ Universiti Malaysia Sarawak \\ Yumni Musfirah Kahar \\ Universiti Malaysia Sarawak \\ Looi-Chin Ch'ng \\ Universiti Teknologi MARA
}

\begin{abstract}
Social media marketing is gaining momentum in recent years due to its ability in reaching out to the target audience in a short period of time. Many forms of social media marketing strategies have been introduced and tested and one that is widely used is Internet memes. Despite its widespread use, there is a need to know if iconicity of memes would be affected when they are used in local contexts. Iconicity refers to the match between form (images and texts) and meanings. This paper reports findings from a qualitative study that investigated the iconicity of memes used in marketing by analysing their language features in relation the feedback obtained from the target respondents namely Malaysian youths. A total of 50 respondents were involved and they were told to rate 30 memes in terms of their level of understanding and interpretation. The subsequent in-depth interviews were conducted on five respondents. The findings show that most of the memes were high in terms of iconicity and only seven of them were low. The predominant language features were also analysed and memes with low iconicity tend to use complex sentences, full of short forms and slangs as well as imperative words. The findings from this study may not be generalised but it has provided insightful outcomes for local businesses in planning their social media marketing especially those that plan to capitalise on the rising trend of Internet memes.
\end{abstract}

Keywords: Memes; Social media marketing; Iconicity, Malaysian youths.

Received: 7 June 2019

Accepted: 16 June 2020

\section{INTRODUCTION}

The marketing of products and services via social media platforms may be regarded as an easier means to reach out to target customers than the need to engage them face-to-face as often the case in conventional marketing strategies. The challenge, though, is to ensure the content designed or produced for social media marketing stands out amidst thousands of postings appearing on each

\footnotetext{
- Corresponding author: Chuah Kee Man, Faculty of Language and Communication, Universiti Malaysia Sarawak, 9400 Kota Samarahan, Malaysia. kmchuah@unimas.my, Tel: +6082583702
} 
potential customer's screen. The continuous display of advertising content in either textual or graphical forms could be convenient to many marketers, but it could also be a frustrating experience as it is not easy to identify what works and what does not (Ilicic \& Webster, 2013). Sajid (2016) aptly pointed out how social media marketing relies on trust and goodwill among sellers and customers and at the heart of this mutually-accepted interaction is how information about products and services are delivered in a manner that is "acceptable" in social media realms. Thus, to achieve the goal of effective marketing in platforms such as Facebook, Instagram and Twitter, the compliance to the common notions of digital advertising may not suffice as many other factors should also be taken into considerations by marketers (Bae \& Zamrudi, 2018).

As reiterated by Tuten and Solomon (2016), a content that receives high engagement within a short period of time can be rather unpredictable and it could go viral because of its "closeness" within a social community. Once a viral content started to penetrate a larger set of community, it transforms into a meme. A meme in general is a piece of information that spreads person to person until it becomes part of general consciousness and it could come in many forms (Tuten \& Solomon, 2016) although the most common type for Internet meme is in the form of graphics with short phrases. Figure 1 shows an example of a meme that went viral during the heat of Facebook's controversy on user data privacy and protection and some businesses took advantage by using this meme to sell their services.

Figure 1: An Example of Internet Meme

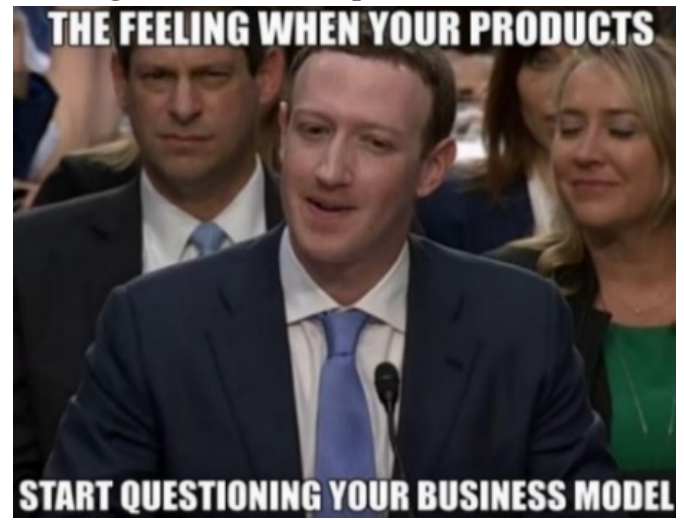

Source: https://meme.xyz/meme/10263

As social media marketing becomes a norm for businesses (from small-media enterprises to even conglomerates), randomly using a meme to highlight products or services has been shown to be ineffective. Studies pertaining to effective use of memes for the purpose of marketing are still lacking in terms of contextualised investigation. While knowledge in this aspect would be able to enhance marketers' use of memes, it also serves as an interesting area for researchers to investigate how certain behaviours or decisions are elicited through memes. Zenner and Geeraerts (2018), for instance, mentioned that intertextuality is crucial in ensuring the graphical representative of context matches the intended message. In cognitive linguistics, this view is related to the semiotic perspective of iconicity, which refers to the closeness between two aspects of a "sign" namely its form and its meaning (Kazmierczak, 2001; Occhino, Anible, Wilkinson, \& Morford, 2017). A 
meme is said to have high iconicity if its message is understood clearly through the graphical representation. Previous studies have found how memes with higher level of iconicity is interpreted more accurately (Cannizzaro, 2016) than those with lower iconicity, and they can go viral in a short time (Sharma, 2018). Despite that, studies done thus far seems to centre on communities where memes are common and strategies used to produce memes for marketing purposes such as humours, metaphors and sarcasm (Benaim, 2018; Casey, 2018; Taecharungroj \& Nueangjamnong, 2015).

There is an apparent need to know if iconicity of memes would be affected when they are used in local contexts or whether localised memes would be effective in conveying the intended meaning. It is also important to know the views of the target audience in finding out what affects their interpretations of the memes. Thus, this paper reports findings from a study conducted on Malaysian youths on their interpretation of various popular memes used across social media platforms. In particular, it seeks to determine the iconicity of memes used in marketing by analysing the language features of the messages delivered through memes in relation the feedback obtained from the youths regarding their interpretations.

\section{LITERATURE REVIEW}

\subsection{Social Media Marketing}

Social media marketing or sometimes known as social media promotion aims to make full use of the online community platforms in marketing products and services aligned to customers' wants and needs (Sajid, 2016; Stephen, 2016). Platforms such as Facebook, Instagram and Twitter are common among users particularly for the youth population (18 to 40 years old) and many companies aim to tap into this enlarging market so as to not only sell their products and services but also to create brand awareness. In doing so, many experts have repeatedly emphasised on the importance of adopting strategic process in creating content for social media marketing. For example, Felix, Rauschnabel and Hinsh (2016) presented a holistic framework in strategic social media marketing that requires cross-functional collaborations to ensure it is effective due to the complex nature of social media. Interestingly, their findings shed some lights on the two contrastive social marketing scopes in terms of content, namely the defender approach that focuses on pushing content to customers such as uploading funny and entertaining content to lure attention, as well as the explorer approach that aims to encourage interactive and collaborative use of social media to engage the customers (Felix et al., 2016). Either way, content is "king", and the expansion of Internet speed and accessibility has placed greater values on multimedia content such as pictures and videos than texts alone. One of the most widely used form of content is memes and the process of selecting popular memes is regarded as important in cultural-embedded branding strategy (Holt \& Cameron, 2010).

\subsection{Memes and the Internet}

The term and concept of memes spawned from Dawkins' (1976) book The Selfish Gene. He suggested the word "meme" as derived from the Greek word of "mimema" which can be translated as "something which is imitated" (Shifman, 2014, p. 10). Instead of retaining the Greek version, he chose to coin "meme" as it sounds closer to "gene". As defined by Dawkins, a meme is a piece 
of information or cultural phenomenon that spreads person to person until it becomes part of general consciousness and it could come in many forms (Olesen, 2009; Tuten \& Solomon, 2016). According to Shifman (2014), a successful meme can be considered as a representative of shared social norms, world views, and user preferences.

On the Internet, the use of memes has grown exponentially due to the convenience of replicating and spreading something via the network, particularly through social media. The Internet meme culture has become so predominant that it has become part of cross-cultural communication mechanism. For example, one can see how a meme created based on American context is replicated to convey a message that is unique to Malaysians. Studies on the use of Internet memes have shown contradictory findings particularly on its corresponding impact in marketing. Taecharungroj and Nueangjamnong (2015) in their study on the communication process of 1,000 humorous memes on Facebook, tested the effect of various styles and types of humour in determining the virality of memes. Based on their findings, it was found that self-defeating style in which the creator of the meme explains his or her own situation in a negative way is the most effective style of humour in luring attention by garnering huge number of shares. Hsu (2018), in her study on borrowed interest appeals in marketing, introduced what is known as "memejacking". It occurs when a brand's advertising includes the imitation or hijack of a meme which is popular at a specific moment. Such strategy seems to work well for many brands as shown in Hsu's reporting of specific advertising cases involving memes.

The use of memes in social media marketing is also growing so as to ensure any products or services can appeal to the younger crowd. Brubaker et al. (2018), however, pointed out the need to look at the strategies in generating memes. Their study on user-generated memes of five top brands in the world (Apple, Google, Coca-Cola, Microsoft, and Toyota) shows how memes not only serves as a way for consumers to bring forth certain opinion on their products in a humorous way but also provided an avenue for organisation to gather useful feedback. It is interesting to note that findings by Brubaker et al. (2018) have highlighted the "value" of memes in social media marketing beyond the typical notion of virality which is loosely measured by total reach (e.g. number of shares, likes or views) of a specific content.

However, some studies have shown that the use of memes in marketing can yield negative impacts particularly on branding. Casey (2018) reiterated the need to relook at the role of memes in creating unhealthy communication among the younger generation. The openness of digital discourse can create prejudice and intensify shaming, which may not be good either for one's mental health or even the image of a brand. As reiterated by Zappavigna (2012), knowing how to use the meme in the correct context is what defined the younger generation definition of "coolness" and in order for one to be accepted to a group. This could also create a problem for products and services that simply jump on the bandwagon by using memes in the marketing content without thoroughly knowing the accuracy of using it or without ensuring whether it is appropriately addressed to the target group so as to ensure they interpret the message correctly. Csordás, Horváth, Mitev and Markos-Kujbus, (2017) demonstrated how user-generated memes could affect brand image as it spreads like virus to illustrate an "alternative meaning" as to what a brand was initially trying to convey. They found out that while memes were useful to generate interests on certain brands, it could also lead to negative portrayal of the brand itself. Figure 2 shows an example of what Csordás et al. (2017) meant, as how the tagline and logo of the popular sports brand was manipulated to convey a different meaning. 
Figure 2: User-Generated Meme on Existing Brand's Tagline

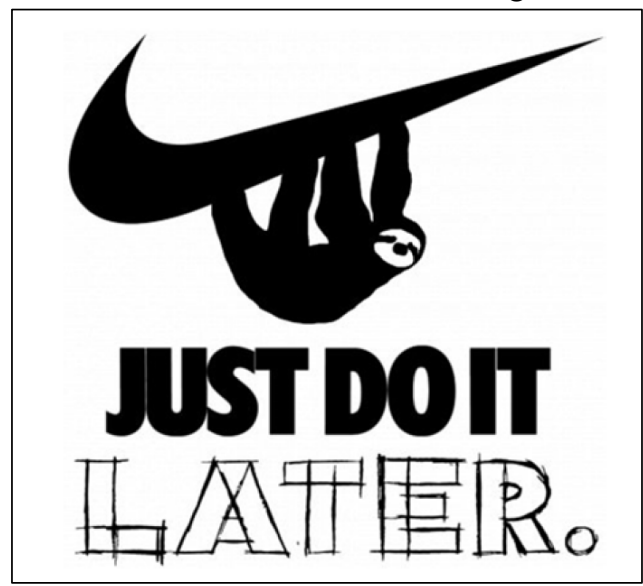

Source: http://realfunny.net/picture-4506-lazy-sloth-advises-you-to-just-do-it-later-.html

Similarly, Sharma (2018) in her article highlighted how some brands such as popular fast-food chains fell short of adopting memes in their advertising strategy that it backfired. Instead of triggering positive feedback, customers ended up giving terrible recounts of their experience with the brand. This greatly shows the importance of putting emphasis in analysing the features of a meme, especially in the investigating the embedded meaning that a meme carries from a linguistics point of view.

\subsection{Memes and the Concept of Iconicity}

Iconicity as a component of cognitive linguistics deals with the relationship between a sign and its object in which the form of the sign recapitulates the object in some way (Kazmierczak, 2001; Mannheim, 1999). Gasser, Sethuraman and Hockema (2005), on the other hand, mentioned that the forms of words somehow suggest their "meanings" or the meanings somehow "motivate" the word forms. In short, iconicity refers to the clarity of the intended meaning through its form. This is where memes can pose a problem. For something to be regarded as a meme, it should be iconic, in a way that it possesses mass cultural awareness that anyone can relate to. Grayson and Martinec (2004) used Peirce's semiotic framework to examine users' perception of offerings in the market through indexical and iconic authenticity and they found out how one's cultural knowledge and historical experience can influence the way they judge what is "authentic". It can be said that the iconicity of any message depends on the effective communication between the marketing practitioner and the perceived meaning by the end users. The more "iconic" a brand is to a person, the higher the chance it can build brand loyalty (Laroche, Habibi, \& Richard, 2013). Ironically, a meme could also bear a lack of context particularly in the case of Internet memes. To use the meme shown in Figure 1 as an example, a person would not be able to understand its meaning if he or she was not aware of the privacy-infringement accusations that Facebook was facing. That meme would cause confusion and open to various interpretations although it would also be possible for people not to recognise Mark Zuckerberg as the co-founder of Facebook. 
Danesi (2018) stressed on this point by stating that the popularity of any content on the Internet can be interpreted differently by every person. The lifespan of a meme's popularity or success also depends upon its ability to be "highly reproducible, recognisable and easily shared" (p. 217). This poses attention to importance of iconicity in meme making. In addition, Csordás et al. (2017) stipulated that a meme should still contain common properties and shared meanings across communities. It is thus the aim of this study to examine the language features of Internet memes used in social media marketing so as to uncover what could aid or impede the interpretation of a target group, i.e. the Malaysian youths.

\section{METHODOLOGY}

This study uses a qualitative research design in order to address its objectives. As the nature of study is to gather deeper understanding of the phenomenon involving Malaysian youths and the use of Internet memes in social media marketing, it is appropriate to examine the gathered data qualitatively. This interpretive approach allows the researchers to seek explanations within the scope of individual consciousness from the viewpoint of the participants in order to provide context-based understanding of the situation being studied (Creswell, 1994).

\subsection{Sample and Sampling Method}

A total of 50 participants were involved in this study. They were selected using purposive sampling technique in which they must fulfil the following criteria:

i. Participants must be Malaysians

ii. They are within the age group of 15 to 30 years old (Youth category as defined in Youth Societies and Youth Development Act 2007 of Malaysia - Amended in 2019)

iii. Good proficiency in English (as all selected memes are in English)

iv. Active social media users - daily visit to social media websites

In terms of social media usage, Facebook and Twitter were visited regularly by all participants (more than once per day). For Instagram, 40 of them were active users while the remaining 15 only use it once or twice per week. They accessed these social media platforms mainly through their smartphones. The participants were sourced through an online survey before they were called up for the data collection sessions. The survey contained information and requirements of the study in which they had to also report their social media usage and exposures to memes as stated above. Those who were not familiar to memes or were not active users of social media were not selected for the purpose of this study. The reason for this exclusion is to avoid those who struggle to understand the concept of memes and thus impede the validity of the collected data.

Out of 75 who participated in the initial survey only 50 participants fit the requirements. They were mostly from the age group of 20 to 22 years old (64\%), 15 to 18 years old $(20 \%), 22$ to 25 years old $(12 \%)$ and 25 to $30(4 \%)$ This age group was chosen mainly due to their exposures to social media as well as their tendency to engage in online shopping or e-commerce (Santha, 2016). This makes it more relevant to investigate how this group of consumers reacts to meme-based social media marketing strategies. 


\section{2. $\quad$ Specimens}

For the purpose of the study, 30 Internet memes were selected as research specimens. To control the type of memes chosen, the researchers decided to select only memes with words (image and text combined) instead of image only as one of the objectives in this study is to examine the language features. Besides that, memes with texts are the most commonly found on the Internet as the text tends to reinforce the embedded meaning in the image (Davison, 2012). The memes were compiled from social media platforms (Facebook and Twitter) through the search feature in which memes were filtered. They were randomly chosen as long as they fit the needed criteria which are memes were used for marketing purposes and were produced in English. These memes could usergenerated but reused by business entities or produced by the businesses themselves. Also, to standardise the comparisons, all memes were of foreign situations as this is to examine if the Malaysian respondents are still able to interpret them. Figure 3 shows two examples of memes used.

Figure 3: Example of Memes Used as Specimens

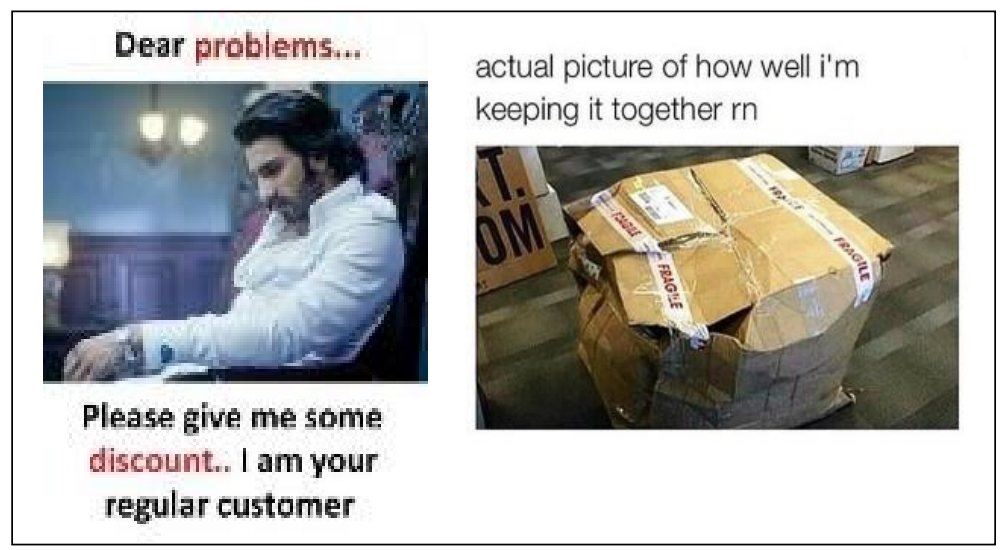

\subsection{Data Collection and Analysis Procedures}

In the first stage of data collection, all specimens were presented to 50 respondents and they were told to rate in a simple scale of three if they were able to understand the memes (3-fully understand; 2-unsure;1- Don't understand at all)They were also asked to provide their reasons if they were unable to understand the meme. In the second stage, five respondents were randomly chosen for in-depth semi-structured interview in order to find out the reasons that affect the iconicity of the memes. They were told to explain how they interpreted each meme and their views on the meme in terms of language features used. This was then followed by a content analysis of each meme by the researchers in uncovering the language features used.

In analysing the iconicity of the memes, the memes which were rated higher by the respondents in terms of their understanding were grouped as high iconicity and those with lower ratings were grouped as low iconicity. For example, if the meme was not able to be understood by at least 30 respondents, they were marked as low iconicity. The researcher also cross-checked their 
interpretation as they were also required to write the meaning in the column provided. If the meaning stated was rather off or odd from the rest of the respondents, they were flagged for further analysis. This step is to ensure the validity of the data collected as the respondents may claim to understand the meme but with a different interpretation. The researchers also made use of the interview session to clarify certain grey areas in order to find out the reasons for any interpretation which is out of the norm.

The interview and content analyses, on the other hand, were conducted using thematic analysis where emerging themes or patterns were thematically coded. The memes were read and analysed and cross-examined by the researchers to ensure reliability of the interpretation and coding schemes. Table 1 shows how this was done.

Table 1: Example of Content Analysis of Memes

\begin{tabular}{|c|c|c|c|}
\hline Memes & $\begin{array}{c}\text { Picture } \\
\text { description }\end{array}$ & Language Features & $\begin{array}{l}\text { How picture affects } \\
\text { perceived meaning }\end{array}$ \\
\hline $\begin{array}{l}\text { When karma comes back on the } \\
\text { people who did you dirty without you } \\
\text { having to exert any energy into being } \\
\text { petty }\end{array}$ & $\begin{array}{c}\text { A famous } \\
\text { artist with an } \\
\text { 'ok' sign }\end{array}$ & $\begin{array}{l}\text { A complex sentence that } \\
\text { talks about karma towards } \\
\text { people you hate. } \\
\text { Binary opposite noted "dirty } \\
\text { - pretty" } \\
\text { No punctuations } \\
\text { Contextual meaning of } \\
\text { "karma" is necessary - but } \\
\text { "comes back on the people" } \\
\text { gives hint on the meaning. }\end{array}$ & $\begin{array}{l}\text { The picture looks like she is } \\
\text { happy because karma hits } \\
\text { the person she hated. So, it } \\
\text { suits well with the } \\
\text { sentences above. } \\
\text { Marketing relevance - } \\
\text { when competitors received } \\
\text { something bad in return of } \\
\text { what they did earlier. }\end{array}$ \\
\hline
\end{tabular}

\section{RESULTS AND DISCUSSION}

In addressing the study's objective of determining the iconicity of memes used in social media marketing, the results from the user rating of the memes were tabulated and compared as shown in Table 2.

Table 2: Classification of Memes Based on Iconicity

\begin{tabular}{cc}
\hline \hline High Iconicity & Low Iconicity \\
\hline M1, M2, M3, M4, M5, M6, M7, M8, M9, M10, & M13, M16, M18, M19, M25, M27, M30 \\
M11, M12, M14 M15, M17, M20, M21, M22, & \\
M23, M24, M26, M28, M29 & 7 memes \\
\hline 23 memes
\end{tabular}

*M=Code for Meme, high when rated highly by more than 30 out of 50 respondents. 
Surprisingly, despite all memes being of foreign situations, only seven memes were rated with low iconicity. These seven memes were not able to be understood by most of the respondents. Figure 4 summarises the results in visual in order to provide a bird's-eye-view of the iconicity results. In a glance, those memes with high iconicity were related to issues that perhaps close to the respondents although the context in the meme was not in local settings.

Figure 4: Visualisation of Memes' Iconicity

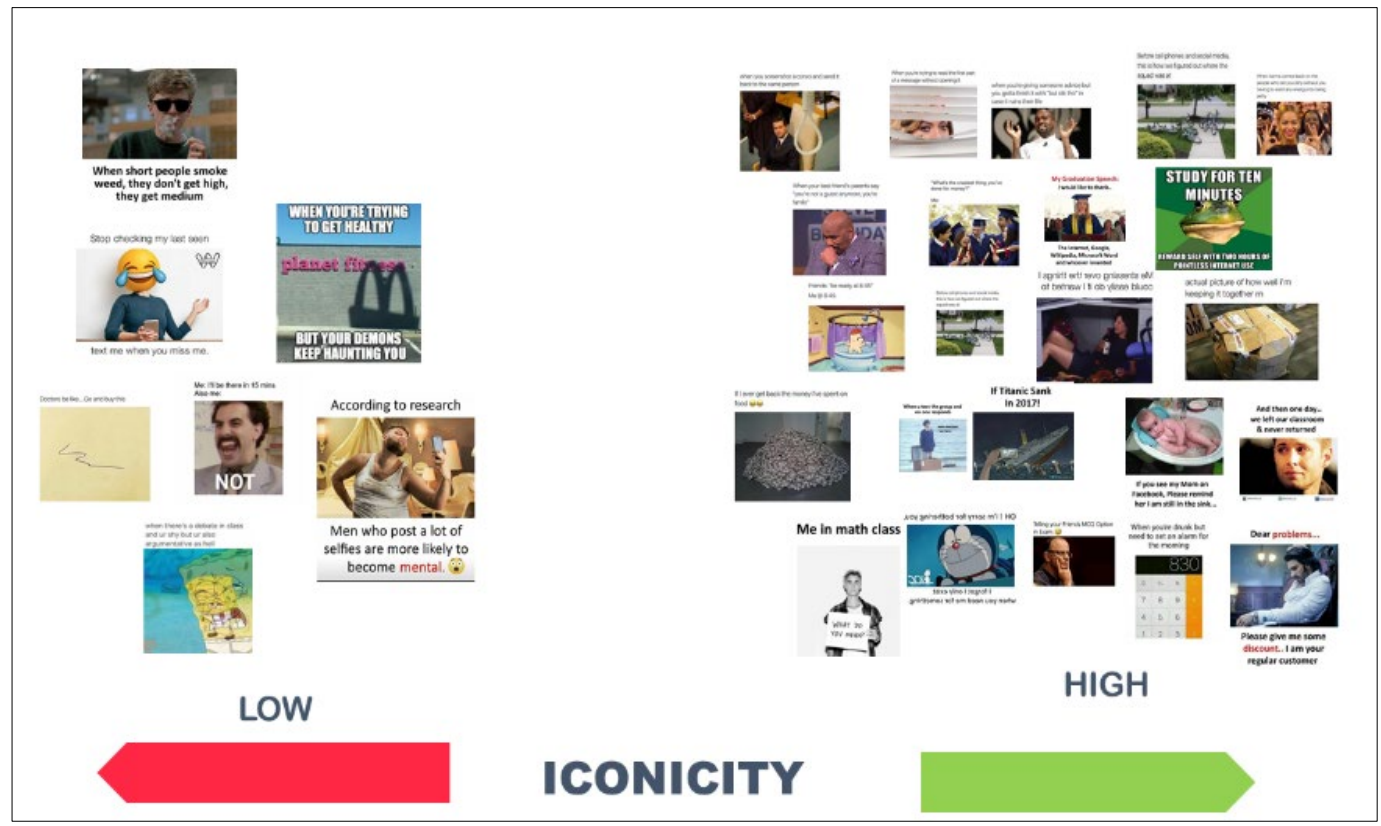

The content analysis of the memes noted that memes with higher iconicity contains texts and images that were closely related to each other as compared to those with lower iconicity. The texts served as the bridge between what was conveyed through the image. For example, M3 as shown in Figure 5, was cheekily used to market a smartphone brand, but yielded an interesting finding. Some respondents did not really know the existence of the mega ship "Titanic" which sank in 1912 but were able to understand the message of the meme accurately as the image shown matches the texts given, and instantly they can relate the behaviour of people now when any mishap happens. 
Figure 5: Example of Meme with High Iconicity

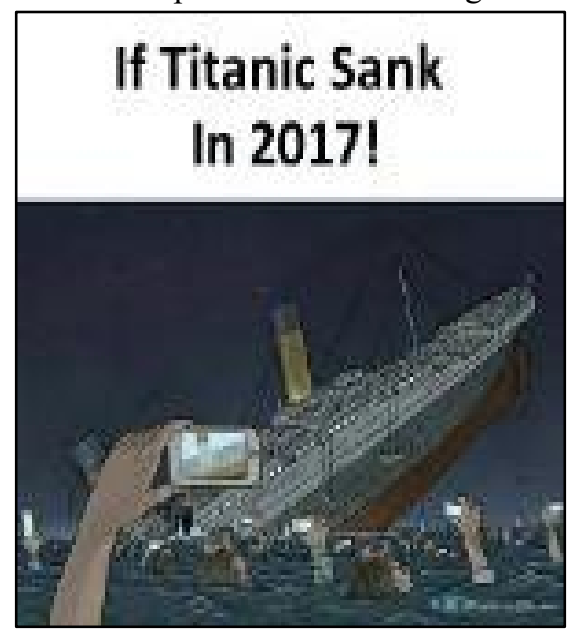

Figure 6, on the other hand, shows a meme which was marked with low iconicity according to respondents of the study. Although the reference to McDonald's fast food chain was clear, most of the respondents did not get the meaning of the line "but your demons keep haunting you". They do not seem to be able to relate the "M" silhouette (McDonald's logo) to the word "demons". Also, during the interview, the respondents also mentioned they do not see McDonald's as demon through the meme as it does not affect their health much. Also, if the meme shows more of the food image (e.g. cheeseburgers and fries), then it would perhaps become easier to understand than showing the logo alone.

Figure 6: Example of Meme with Low Iconicity

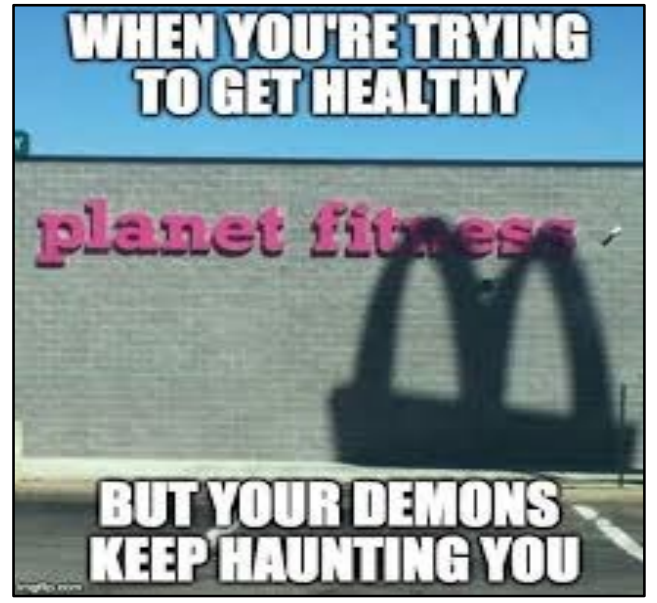


These results echo what Csordás et al. (2017) mentioned as having features that are universally understood and ultimately increases the iconicity of the memes. The cultural context may not affect the meaning conveyed as long as the reference through the choice of image and texts is aptly chosen. As emphasised by Gasser et al. (2005), iconicity can work when meanings are inspired by the signs (words, images) chosen. Thus, any efforts to use memes as part of social media marketing should not avoid this importance. It is not enough by merely selecting a meme to loosely relate to the product or services. It has to be straightforward yet meaningful. Also, it is worthy to note that memes with higher iconicity tend to be viral faster than those other memes.

In terms of language features, this study also managed to notice several pertinent features as summarised in Table 3. The types of language features were elicited from the respondents and content analyses of the memes, in which similar patterns or feedback were grouped under one type.

Table 3: Language Features Used in Memes

\begin{tabular}{|c|c|c|}
\hline $\begin{array}{c}\text { Types of language } \\
\text { features }\end{array}$ & Memes with Low Iconicity & Memes with High Iconicity \\
\hline Sentences structure & $\begin{array}{ll}\text { - } & \text { Compound/Complex } \\
\text { sentences } \\
\text { - } & \text { Incomplete or dangling }\end{array}$ & $\begin{array}{l}\text { - Mostly simple sentences } \\
\text { chunked together } \\
\text { - Complete }\end{array}$ \\
\hline Word Choice & $\begin{array}{l}\text { - Using too many short forms } \\
\text { (Ur, bt, idk, imho) } \\
\text { - } \quad \text { Culturally-bound or slangs } \\
\text { - } \\
\text { More third-person pronouns } \\
\text { (they, he, she, them) }\end{array}$ & $\begin{array}{l}\text { - } \quad \text { Limited use of short forms } \\
\text { - Common words (minimal } \\
\text { slangs) } \\
\text { - More personal pronoun of } \\
\text { "I, me, we" }\end{array}$ \\
\hline Writing Style & $\begin{array}{ll}\text { - } & \text { Situational description (When } \\
\text { - } & \text { Inu....) } \\
\text { Instructions (Stop, Do...) }\end{array}$ & $\begin{array}{ll}\text { - } & \text { Situational description } \\
\text { - } & \text { Conditional (if....) } \\
\text { - } & \text { Presenting something } \\
& \text { negative to lure positive } \\
& \text { responses }\end{array}$ \\
\hline
\end{tabular}

With regards to sentence structure, memes with low iconicity were noted to be using more simple sentences with less complex structure. In addition, if more description is provided, they are done by using more than one simple sentence instead of combing them as complex sentences. For example, "And then one day. We left out classroom and never returned". Long sentence structure seems to impede the iconicity of the memes especially when no punctuations are used, causing it to be dangling (e.g., when doctor said go and buy). In terms of word choice, memes with high iconicity uses more personal pronouns and avoided the use of too many short forms or culturallybound slangs (e.g., demons - which may not be common to Malaysians). The researcher noted that the respondents prefer memes that sound personal perhaps it resonates their own experience. Memes that used third-person pronouns implied they are not relevant to the respondents' life. 
Also, in terms of writing style, memes with higher iconicity avoided instruction-based sentences such as "Stop reading my last seen" and used more conditional style like "If I ever get back the money I've spent on food". This could be related to the denotation of imperative words like "stop" that sounds demanding and authoritative. Moreover, the researcher found similar pattern to what was found by Taecharungroj and Nueangjamnong (2015) in which memes with "self-defeating" messages were largely high in terms of iconicity. A clear example of this is shown in Figure 7, which shows how a person admitted his dislike of mathematics although not all may have heard of Justin Bieber's song of "What do you mean?" they can still relate to this meme easily. In terms of marketing, this is would help promote services related to math classes or products related to easy or fun learning of maths. It shows the power of memes in generating interest and user engagements (Hsu, 2018).

Figure 7: Example of Self-Defeating Meme

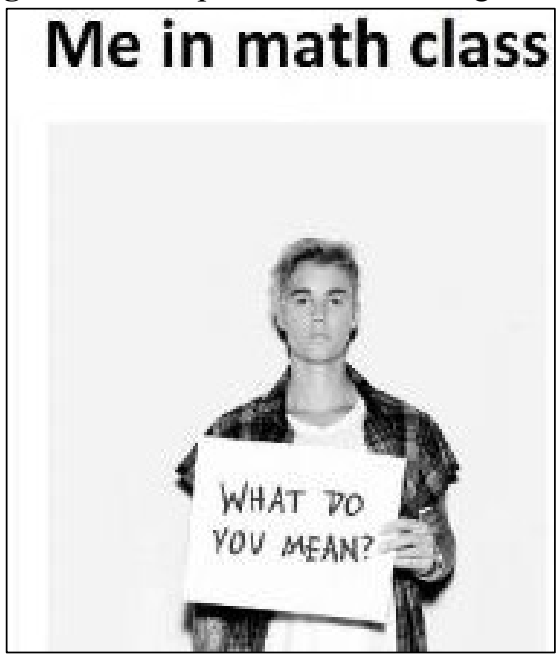

\section{CONCLUSION}

Although this study is confined to a small set of memes and sample size, it has shed very interesting light as to how memes are interpreted by Malaysian youths. This study also adds to the body of knowledge on the impact of memes in marketing from the perspective of iconicity. The notion of culturally-biased memes is debateable as memes with high iconicity can still reach the target audience despite being culturally different as shown in the findings of this study. Memes that were produced using foreign situations were still understood accurately by the respondents. However, this is not denying the influence of culture as the outcomes of this study also pointed to the fact that users with greater exposure to different cultures are able to appreciate the intended meaning of the memes faster than those who do not. The lack of slangs in memes with high iconicity indicates that culturally-bound words may disturb understanding. Also, the researcher also noted how memes may not be funny in nature as the respondents reacted to the memes based on their understanding of the message rather than the jokes per se. Not many of them laughed at the memes 
but they got the message right. Nevertheless, further study can be done in comparing locally produced memes as a comparison to foreign memes in order to further uncover the features within memes that could affect understanding as the in-depth interview conducted in this study was limited to only five respondents. The selection of the memes could also be improved by specifically looking at certain brands.

The findings from this study are important for businesses and marketing practitioners in planning their social media marketing especially those that plan to capitalise on the rising trend of Internet memes. The language features identified earlier show how companies can actively engage their target consumers by using simple and straightforward language. The key seems to be on the relationship between text and image so much so that they can affect the actual message of the meme. It is also advisable for companies to keep up with what is trending in social media so that the memes used in marketing is not perceived as outdated. Therefore, careful attention is needed in matching the right meme with the right message of products and services, so that the customers know it "memes" business and not merely for fun.

\section{REFERENCES}

Bae, I. H., \& Zamrudi, M. F. Y. (2018). Challenge of social media marketing and effective strategies to engage more customers: Selected retailer case study. International Journal of Business \& Society, 19(3), 851-869

Benaim, M. (2018). From symbolic values to symbolic innovation: Internet-memes and innovation. Research Policy, 47(5), 901-910.

Brubaker, P. J., Church, S. H., Hansen, J., Pelham, S., \& Ostler, A. (2018). One does not simply meme about organizations: Exploring the content creation strategies of user-generated memes on Imgur. Public Relations Review, 44(5), 741-751.

Cannizzaro, S. (2016). Internet memes as internet signs: A semiotic view of digital culture. Sign Systems Studies, 44(4), 562-586.

Casey, A. (2018). The role of Internet memes in shaping young people's health-related social media interactions. In V. Goodyear \& K. Armour (Eds.), Young People, Social Media and Health (pp. 162-176). London, UK: Routledge.

Csordás, T., Horváth, D., Mitev, A., \& Markos-Kujbus, E. (2017). User-generated internet memes as advertising vehicles: Visual narratives as special consumer information sources and consumer tribe integrators. In G. Siegert, M. B. Rimscha, \& S. Grubenmann, Commercial Communication in the digital age (pp. 274-266). Berlin, Germany: Walter de Gruyter.

Creswell, J. W. (1994). Research design: Qualitative \& quantitative approaches. Thousand Oaks, CA: Sage.

Danesi, M. (2018). There's more to perfume than smell: Advertising, pop Culture, and meme culture. In Of cigarettes, high heels, and other interesting things (pp. 205-221). New York, NY: Palgrave Macmillan.

Davison, P. (2012). The language of Internet memes. In M. Mandiberg (Ed.), The social media reader (pp. 120-134). New York, NY: NYU Press.

Dawkins, R. (1976). The selfish gene. Oxford, UK: Oxford University Press.

Felix, R., Rauschnabel, P. A., \& Hinsch, C. (2017). Elements of strategic social media marketing: A holistic framework. Journal of Business Research, 70, 118-126. 
Gasser, M., Sethuraman, N., \& Hockema, S. (2005). Iconicity in expressives: An empirical investigation. In S. Rice \& J. Newman (Eds.), Experimental and empirical methods (pp. 163-180). Stanford, CA: CSLI Publications.

Grayson, K., \& Martinec, R. (2004). Consumer perceptions of iconicity and indexicality and their influence on assessments of authentic market offerings. Journal of Consumer Research, 31(2), 296-312.

Holt, D., \& Cameron, D. (2010), Cultural strategy: Using innovative ideologies to build brands, New York, NY: Oxford University Press.

Hsu, C. K. J. (2018). The 'borrowed interest' appeal: Brands riding the wave of popular events and memes in the digital age. Journal of Brand Strategy, 7(3), 258-270.

Ilicic, J., \& Webster, C. M. (2013). Celebrity co-branding partners as irrelevant brand information in advertisements. Journal of Business Research, 66(7), 941-947.

Kazmierczak, E. T. (2001). Iconicity, diagrammatics, and aesthetic preferences: A semiotic perspective on visual literacy and information design. Visual Studies, 16(1), 89-99.

Laroche, M., Habibi, M. R., \& Richard, M. O. (2013). To be or not to be in social media: How brand loyalty is affected by social media?. International Journal of Information Management, 33(1), 76-82.

Mannheim, B. (1999). Iconicity. Journal of Linguistic Anthropology, 9(1/2), 107-110.

Occhino, C., Anible, B., Wilkinson, E., \& Morford, J. P. (2017). Iconicity is in the eye of the beholder. Gesture, 16(1), 100-126.

Olesen, M. (2009). Survival of the mediated. Copenhagen, Denmark: University of Copenhagen.

Sajid, S. I. (2016). Social media and its role in marketing. Business and Economics Journal, 7(1), $1-5$

Santha, S. (2016). Online shopping behaviour among youth. International Journal of Research in Social Sciences, 6(3), 368-385.

Sharma, H. (2018). Memes in digital culture and their role in marketing and communication: A study in India. Interactions: Studies in Communication \& Culture, 9(3), 303-318.

Shifman, L. (2014). Memes in digital culture, Cambridge, MA: MIT Press.

Stephen, A. T. (2016). The role of digital and social media marketing in consumer behavior. Current Opinion in Psychology, 10, 17-21.

Taecharungroj, V., \& Nueangjamnong, P. (2015). Humour 2.0: Styles and types of humour and virality of memes on Facebook. Journal of Creative Communications, 10(3), 288-302.

Tuten, T. L., \& Solomon, M. R. (2017). Social media marketing. London, UK: Sage Publication.

Zappavigna, M. (2012). Discourse of Twitter and social media: How we use language to create affiliation on the web. London, UK: Bloomsbury

Zenner, E., \& Geeraerts, D. (2018). One does not simply process memes: Image macros as multimodal constructions. In E. Winter-Froemel \& V. Thaler (Eds.). Cultures and Traditions of Wordplay and Wordplay Research (pp. 167-193). Berlin, Germany: Walter de Gruyter. 